https://doi.org/10.5719/aub-g/70.1/9

\title{
LOGICAL FRAMEWORK ANALYSIS AS TOOL FOR SUSTAINABLE REGENERATION IN THE URBAN-RURAL INTERFACE
}

COSMINA-ANDREEA MANEA ${ }^{1}$

\begin{abstract}
Territorial regeneration is needed for most spaces situated on the edge of large cities. Due to the strong influence of the city, they lack the necessary resources to attract investments and to create a sustainable development. Logical Framework Analysis (LFA) can be used to identify the main actors, their resources, the problems and their causes, as well as the long, medium and short-term objectives and the necessary actions needed to achieve them. Feldioara commune, a rural area near Brasov Municipality, managed to identify its natural resources, to attract industrial enterprises from the city, and, in the same time, to create a strong community and local identity. By analyzing statistical data from the last years and the LFA structure, we can trace back how they managed to achieve sustainability and extract some general actions with a high degree of replicability in many other settlements situated in the urban-rural interface.
\end{abstract}

Keywords: urban-rural interface, logical framework analysis, regeneration, sustainability

\section{Introduction}

Territorial regeneration represents the structured and integrative functional conversion of spaces that leads to a betterment of economic, physical, living and environmental conditions (Pourzakarya and Bahramjerdi, 2019). For a sustainable rural regeneration all actors must be actively involved (Safonte and Trapani, 2017; Gao and Wu, 2017) and all local resources must be used efficiently. This way, regeneration leads

\footnotetext{
${ }^{1}$ PhD student Doctoral School Simion Mehedinti - Nature and Sustainable Development, University of Bucharest, E-mail: cosmina.manea@drd.unibuc.ro
} 
to local identity formation, which includes local pride, community formation, place memory and attachment (Reid et al., 2020).

Also, the triple bottom line concept is essential when implementing sustainable regeneration strategies. This concept was created in 1994 and stated that there is a direct link between the economic performance of an entity and its social and environmental performances (Grankvist, 2009). That was the moment when public and private institutions realized for the first time their impact on environment and on society is affecting the economic performance, and also the moment when investment in community activities, people welfare, sustainable resource consumption, efficient waste management, effective land use began (Maloni and Brown, 2006). If any regeneration projects only respect two of those three dimensions, the project will be agreeable (environment and society dimensions), equitable (society and economy dimensions) or viable (environment and economy dimensions), but it will not be sustainable. (Guzman et al., 2017; Tweed and Sutherland, 2007; Cucari et al., 2019)

The most important drivers within these three dimensions are ethics, morals and values. More precisely, economic dimension concerns financial prospects such as GDP growth, employment and tax revenue. Environmental dimension concerns the effect the functional profile of the settlement has on nature, as preserving the environment for the next generations is one of the goals of sustainability practices. The main focus of social environment is related to social systems, social cohesion, health issues, human rights, labor rights, etc. and aims at creating a local identity and community (Guzman et al., 2017).

Rashid (2015) has, however, an interesting perspective, considering that regeneration means more than sustainable transformation of a settlement, as it means not only to preserve resources for the next generations, but also to better the environment, with actions that have an impact on functional, social and cultural levels.

The urban-rural interface represents a distinct space, neither urban, nor rural, with unique characteristics taken from both type of settlements, with a strong dynamic and fast evolution, that marks the transition between the densely build city and the villages dominated by natural landscapes (Lopez-Goyburu and Garcia-Montero, 2018). The Encyclopedic Dictionary of Landscape and Urban Planning defines the urban-rural 
interface as an area of land on the boundary of an urban area, which forms a transition zone or an interface between the build-up area and the open landscape of the countryside. Viewed as a landscape in itself, it is often an area in which the interaction of urban and rural land uses leads to conflict (Evert, 2010).

Places on the urban-rural interfaces are located under the strong influence of the polarizing urban-center and suffer intense dynamics and evolution from a demographic, functional, economic, etc. point of view (Yao et al., 2018; Ianoș and Jones, 2019). Industrialization, delocalization, suburbanization, as well as the increased freedom of movement are all important factors affecting the spaces situated on cities' edges (Ianos, 2004). The changes are often dramatic, and the loss of local identity is so fast and strong that those places no longer identify neither with the initial culture, or the culture of the new commers (Nilsson et al., 2013). Also, territorial planning in the interface is chaotic, with the territory being more fragmented than integrated, while the local authorities lack the planning instruments that could create regeneration and smart development (Ianos et al., 2021). This is why there is a urgent need for development guidelines in the urban-rural interface.

\section{Methodology}

The main objective of this paper is to give an example of a proper way of sustainably regenerating a space in the urban-rural interface of Romania. The case study considered is Feldioara commune, located in the urban-rural interface of Brasov Municipality (fig. 1). Feldioara is situated in Brasov metropolitan area and it is one of the villages strongly influenced by Saxon and Hungarian populations. It has a rich cultural patrimony (Teutonic fortress, historical and memorial monuments, architectural sites, natural protected areas, traditional festivals and gatherings, etc.), as well as a high level of infrastructural development. It is composed of three villages (Feldioara, Rotbav and Colonia Reconstructia) and it is one of the most developed rural areas in Romania, as a result of the measures taken by local authorities. 


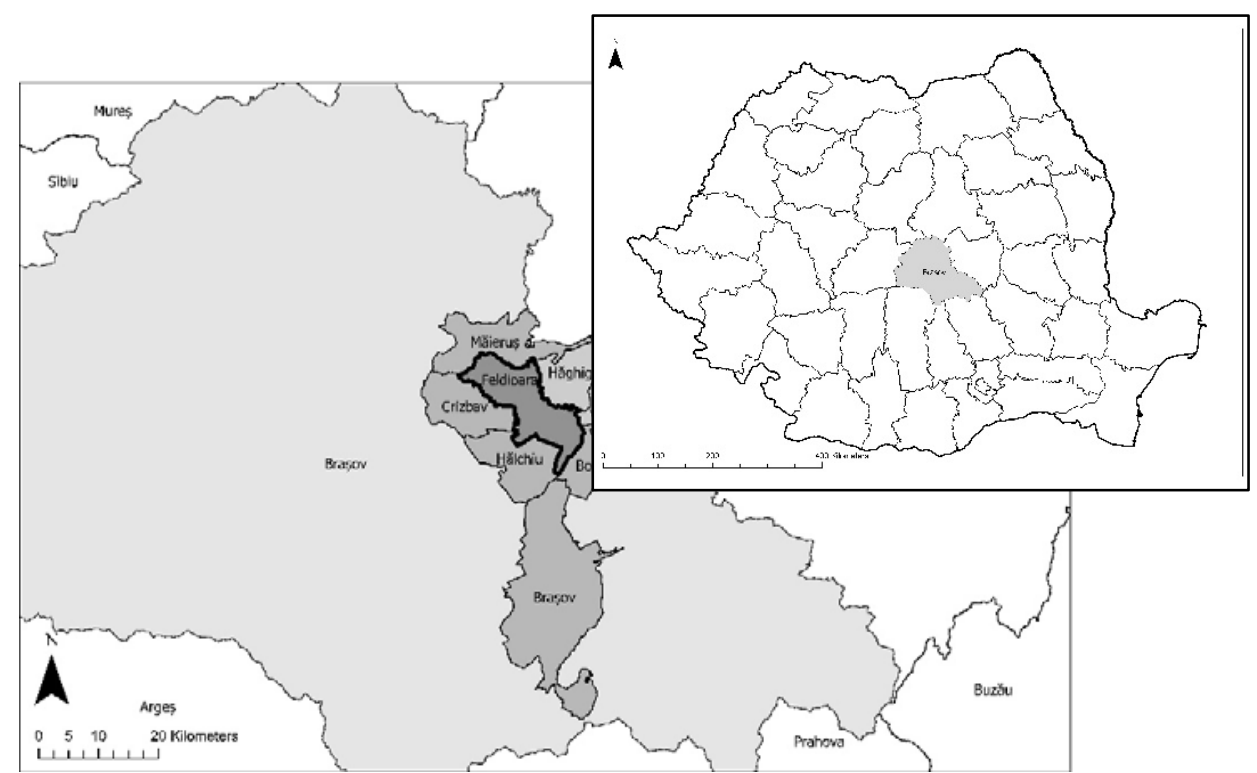

Figure 1. Location of Feldioara commune

Source: created in ArcGis Pro 10.3.1

Feldioara is located in the metropolitan area of Brasov municipality, with which it has strong links, flows and connections. Brasov ensures for Feldioara a series of services like metropolitan transportation and social centers, while Feldioara offers a space in which it can expand its industrial zone, a tourist point based on rural lifestyle, as well as a young qualified workforce supplier. In relation with neighborhood settlements, Feldioara is a services supplier, especially regarding work places, preuniversity education, medical services, tourism, recreation and culture.

The infrastructure is very well developed: $90 \%$ of houses have water supply, $82 \%$ sewerage coverage, $98 \%$ electricity, 32\% central heating, $97 \%$ kitchen inside the house, $82 \%$ bathroom inside the house (National Institute of Statistics, 2011 Census). The commune is crossed by European highway E60, which makes the place highly accessible (only 15-20 minutes by car to Brasov). Over $90 \%$ of roads are paved. When it comes to medical services, there are 16 permanent medics and a SMURD center. Schools are also a central point of interest for authorities, with 3 secondary schools and one high school situated in Feldioara. 
Demographically, population is increasing, but there are strong changes from ethnic point of view, as the Saxon population, a majority before 1990, remained with only 300 members in 1990, 67 in 2002, 37 in 2011 and only 9 members in 2019 (National Institute of Statistics, 2021). In the same time the Roma minority shows a strong increase (from less than $1 \%$ of the total population in 2002 , to almost $3.5 \%$ in 2019), while the Hungarian population remains constant (around 7\%) (National Institute of Statistics, 2021).

The cultural profile of the commune is represented by the many natural and anthropic monuments, as well as by the high number of festivals, traditions and customs. Among the intangible cultural patrimony elements we can name Marienburg Fortress (medieval Teutonic citadel), two medieval Evangelic Churches (in Feldioara and Rotbav villages - the second being half destroyed after the tower collapsed in 2016), Orthodox Churches of Feldioara and Rotbav (both more than 100 years old), Monument of Saxon hero students, Monuments of Soviet and Hungarian prisoners, Monument of Romanian heroes, the Saxon schools, the architectural site Rotbav, the Saxon community center, the Saxon architecture, the Rotbav lakes and forest, etc. Of those, only the Monument of Saxon hero students, the churches and the fortress can be visited in organized manner. Most tourists can, however, enjoy during every visit a different experience, as there are numerous activities taking place inside the commune, which represent a part of its intangible cultural patrimony. Among those, we can name the monthly social gatherings / sezatori (where old people, artists and craftsmen share their knowledge with the young generation), the spring fair, Rusalii Celebration, Armindeni festival, medieval knights and ladies' festival, Burdioazele masked parade, traditional and medieval music festivals, winter fair and Christmas festival, Sanziene Celebration, traditional medieval games festival, pensioners prom, movie nights in the fortress, etc.

For the completion of this paper, several visits and discussions with members of local administration (including the mayor Eng. Sorin Taus) were made. Also, statistical data from both the National Institute of Statistics and the local Tourism Information Center were collected, as 
well as 80 questionnaires. The questionnaire method was used in order to evaluate the social capital, to identify whether there is a strong local identity and to assess the level of civic participation of population. The sample is representative, as $1 \%$ of the total population of 7603 inhabitants was questioned. The respondents were mainly female $(62.5 \%)$, while the median age was 38 years old. As the level of education is concerned, most of the respondents have as a last absolved level of school either gymnasium or lyceum.

\section{Results and discussion}

At local level, sustainable regeneration can be achieved by using the local cultural and social patrimonial resources. In order to efficiently use the local resources, a proper strategy is needed, for which the LFA (Logical Framework Analysis) can be used (Ianos, 2004). This analysis is usually used in management and development projects planning and it is an instrument oriented towards objectives. It implies the structural arrangement of a project elements by highlighting the logical links between resources (inputs), planned activities and results (outputs).

The first step in LFA analysis is to identify all interested actors, their problems, needs, interests and potential resources, as well as the possible links between them (fig. 2). In case of Feldioara commune, the interested actors can create an ad hoc Task Force type constitutive structure, capable of implementing the rural development strategy based on the endogenous potential.

Those actors can be grouped in five main categories:

a. Public services and institutions (Local Council, District Council, Tourism Information Center, neighborhood localities) - all have a high interest in the area, a high administrative capacity, but only medium resources. Their main objective is local development, increase of life quality, exchange of capital, resources and population, collaboration in implementing projects capable of solving common problems.

b. Private institutions providing public services (Romanian Orthodox Church, Evangelical Romanian Church, local schools and Theoretical High School Petru Rares) - all have a medium interest in the area's development, but for different reasons: existence of old architectural 
monuments or attracting more customers for their services. However, their resources are limited, as well as their capacity of mobilizing them.

c. Private companies and economic agents (Doripesco fishing company, local restaurants, Marienburg guesthouse, Miele lather fabric, Olympus food processing factory, Reiner salami fabric, etc.) - all have high resources, high capacity of mobilizing them and a strong interest in developing the infrastructure in the area. Their goal is economic profit and in exchange for any benefit from local administration they are willing to invest also in social and environmental projects.

d. Non-profit sector (Intercommunity Development Association Brasov, Local Action Group Tara Barsei, other NGOs) - all have a high interest in development, high capacity of resource mobilization and management, but only very limited resources.

e. Other relevant local actors (local community, local artists and manufacturers, local and district press) - they all have a high interest in the area and a high resource capacity, but they need to be supported and organized by the other actors in order to reach their potential.

The second phase of LFA analysis is represented by problem identification, the main problem in Feldioara being the need for a local sustainable social and economic development. From this problem, the following secondary problems (numbers) could have been identified five years ago, with their main causes (letters):

1.Underuse of cultural patrimony potential: a. there are potential patrimony buildings and sites not included in tourism circuit; $b$. evangelical churches are in high degree of deterioration; c. the architecture of Saxon houses was changed by the new inhabitants; d. Vandalism and criminality is manifested through graffiti and waste not properly deposited; e. there is a strong tourism seasonality; f. local tourism is focused on the fortress; g. modern technologies are not sufficiently used for tourism marketing. 


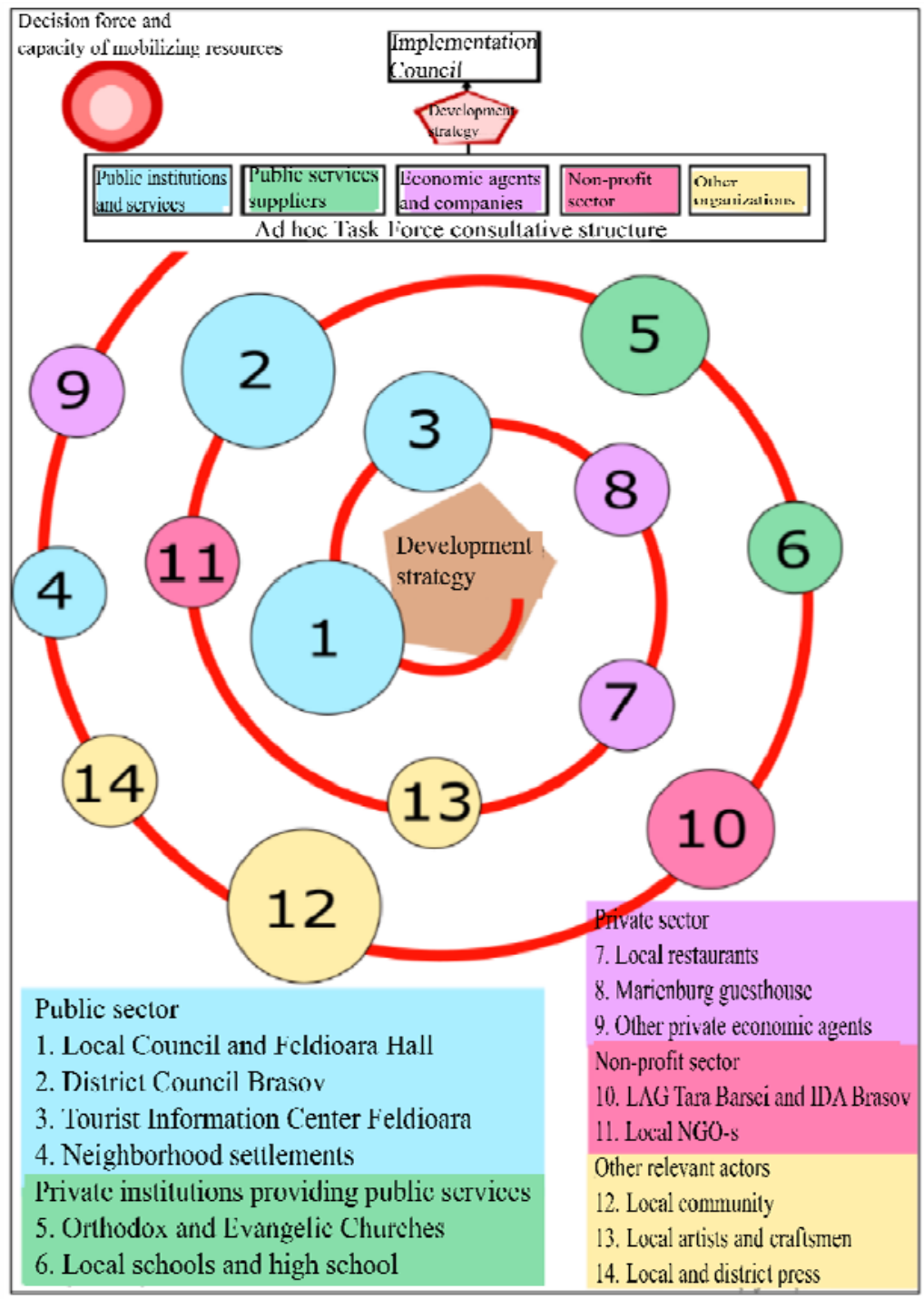

Figure 2. Main actors with interest in Feldioara commune development based on their sector of activity, their degree of interests and their resource capabilities

Source: graph created in Inkscape program based on interviews with local authorities and the model proposed by Haelg et al., 2020 and the Local Development Strategy of Câmpia Turzii, 2015 
2.Underuse of social patrimony potential: a. lack of actions for which local people can volunteer; b. lack of promotion and support of local artists and crafters; c. low number of entrepreneurs and small enterprises; $d$. low number of events involving civic actions and social interaction; e. insufficient promotion of some unique local events and traditions like Burdioazele.

3. Low number of public-private and private-private partnerships: a. lack of a thematic local tourism cycle; b. low number of economic agents involved in local tourism; c. lack of interest and involvement of owners of patrimonial monuments; d. many economic actors from the food and textile sector that are not actively involved in local community projects.

4. Low quality of work force: a. population ageing; b. low local retention of work force; c. low level of education; $d$. high unemployment and poverty rates; e. increasing number of commuters and transformation of the commune in a bedroom-village.

5. Low accessibility: a. very old buses, with high prices and large intervals between leaves; $b$. historical monuments situated at distance from the main road and from each other; c. low number of tourist accommodation.

After identifying all those problems, the next component of the LFA analysis is to identify the main project's elements: the long-term strategy (social and economic development), the medium-term objectives (A to E), the main activities through which they can be implemented (small letters) as well as the SMART indicators, the methods for solution evaluation and monitorization, etc. For the purpose of providing a guideline for other settlements with similar conditions as Feldioara, the activities are the last level detailed in this paper, as the rest of them are specific to each place and the replicability level is too low to be relevant for other territories.

A. Efficient use of cultural patrimony: a. introduction of all cultural patrimony objectives in the touristic circuit so that all population can have access within a 15 minute walk to a cultural site (fig. 3 and 4); b. renovation and restauration of cultural monuments (by now the 
fortress was rebuilt); c. conservation of architectural elements with traditional value through urbanistic rules; $d$. increase of protection and conservation of historic monuments by increasing awareness about their value; e. creating local activities like festivals and celebrations during winter time, when the number of tourists is very low; e. individualizing tourist's experiences for instance by their welcoming by a man dress in a knight or by a lady in medieval dresses; f. creating an experience tourism based on a circuit, not a single monument; g. using virtual reality techniques in presenting patrimony objects.

B. Efficient use of social patrimony: a. increasing the activities for which locals can volunteer (according to questionnaires, 50\% of respondents want to volunteer but they have no available opportunity); b. promoting and supporting local artists and craftsman (the local monthly gatherings called sezatori are a national tradition revived locally, that creates local identity, community belonging and supports local arts); c. increasing the numbers of entrepreneurs and investing in small and medium enterprises (more than $80 \%$ of respondents could easily identify possible business ideas that the community needs or that could improve the quality of life and services significantly and were not available locally, like the lack of a souvenir shop); d. Increase in number of events involving social interaction and civic action (e.g. the high school students are guides in the fortress during summer, people participate as volunteers to dress in medieval clothes or to create an artistic moment during celebrations); e. promoting some unique local events and traditions like Burdioazele and Sanzienele mainly through press and at tourism fairs, but also through local people, of which most interact with tourists at least once per week $(70 \%$ of questionnaire respondents declared that they interact with tourists once or twice per week).

C. Increase in number of public-private and private-private partnerships: a. creation of a local thematic tourism circuit involving all neighborhood settlements, as well as the local economic actors to provide food and products; $b$. increase of economic agents in tourism sector (by creating a local tourism information center, as well as a guesthouse); c. creating partnerships with owners of valuable historical monuments; 
d. creating partners with local economic agents (e.g., Miele provides clothes for medieval festivities, Doripesco gives a significant discount for all tourists, Reiner brings horses and traditional meals for important events).

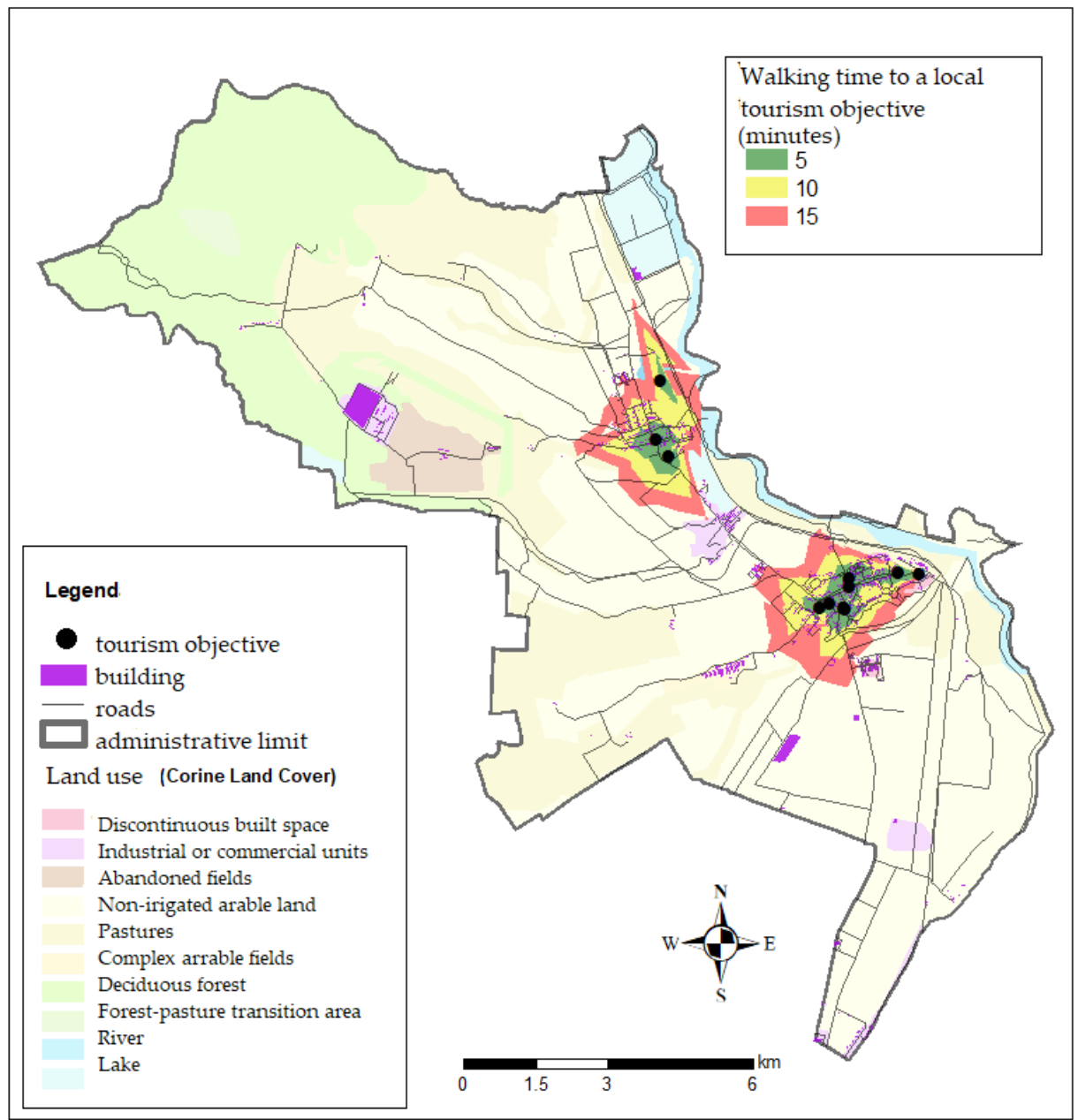

Figure 3. Population accessibility within 15 minutes walk to any tourist objective before the introduction of all objectives into the tourist circuit Source: created in ArcGis Pro and using CLC and Open Street Maps data 


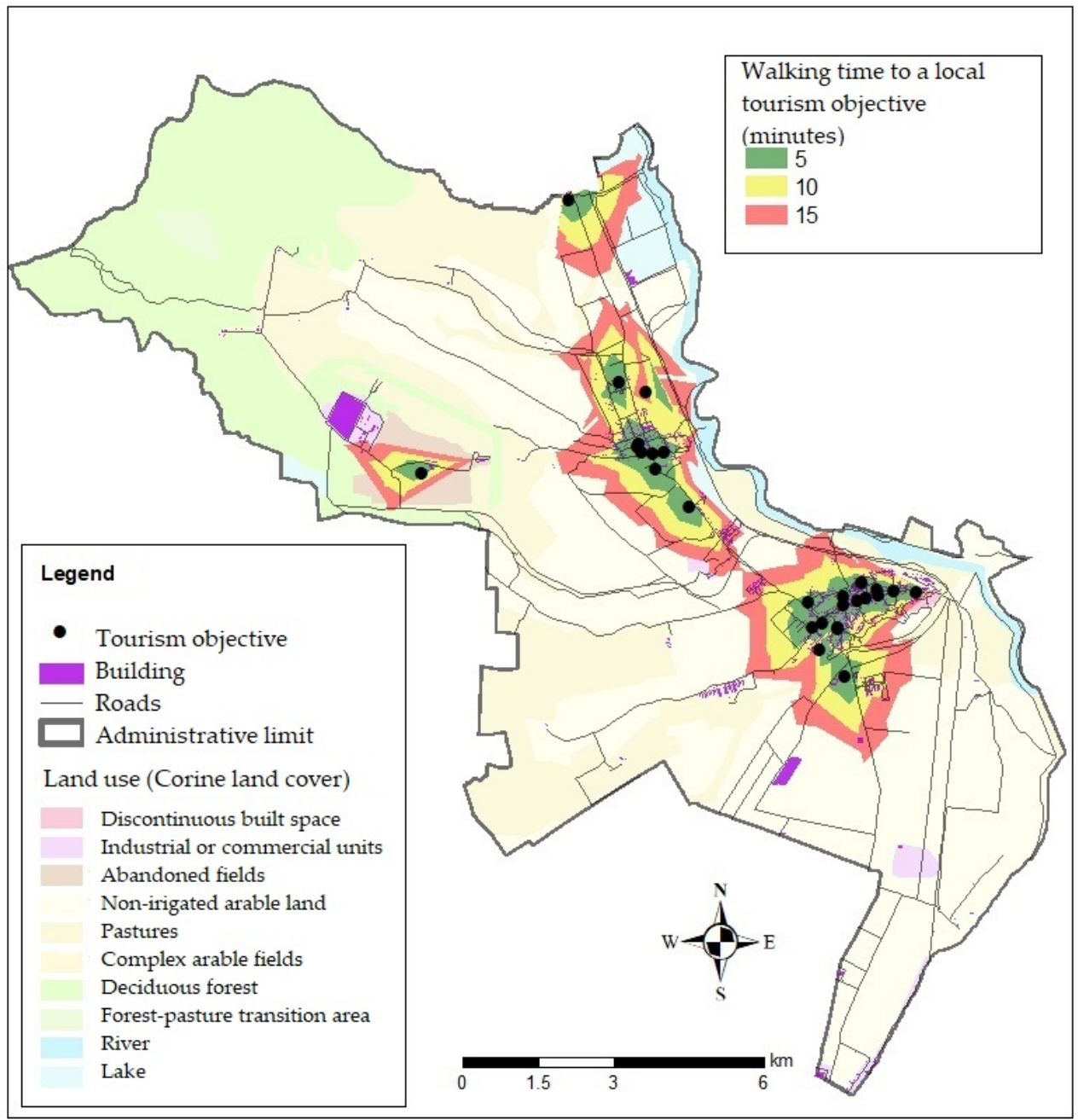

Figure 4. Population accessibility within 15 minutes walk to any tourist objective after the introduction of all objectives into the tourist circuit Source: created in ArcGis Pro and using CLC and Open Street Maps data

D. Increasing the quality of workforce: a. Attracting young people (high school students are guides in the fortress during summer and can work part time in tourism, schools have been renovated and have state of the art technology); b. creating local workplaces (by attracting nonpolluting industries from Brasov city); c. increasing quality and access to education by improving study conditions; d. lowering unemployment 
and poverty by identifying vulnerable population and collaborating with district social services, especially in case of Roma population; e. rural migration and attracting permanent population instead of commuters by providing both working places and better environmental conditions than the city.

E. Accessibility improvement: a. buying new busses and providing metropolitan transportation in collaboration with Brasov municipality; b. Increase of road signs number and creation of speed limitations to improve safety; c. Increase in number of tourism accommodation sites (Marienburg guesthouse).

\section{Conclusion}

Feldioara, a commune near Brasov municipality, by efficient local development strategies, has managed to implement a large number of projects and solutions, becoming an attractive space for investors and population and reversing the descended trend that most Romanian places near cities face from an economic and environmental quality point of view. Cultural patrimony, rural regeneration, social patrimony and local partnerships have all been analyzed separately before (Cercleux et al., 2012; Carvalho-Ribeiro et al., 2016; Beel et al., 2017; Cucari et al., 2019), but an integrated analysis at local level, like the one LFA analysis can provide, have only been undertaken in some places in north-western Romania, in Maramures or in areas affected by deindustrialization (Corsale and Iorio, 2014; Borza and Manolescu, 2015; Catrina, 2015; Cercleux and Bole, 2019), where the local cultural conditions do not allow a high degree of replication. The solutions presented in this case study have a high degree of replicability in all spaces in search for their local identity due to pressures of urbanization, urban migration and industrialization, as it is the case of Feldioara.

By analyzing how local authorities in Feldioara managed to efficiently use and highlight the full potential of local cultural and social patrimony, a series of measures and initiatives that can be replicated for conservation, restauration and marketing of other similar places can be observed: renovating historical monuments, creating festivals and keeping local traditions alive, creating local gatherings and crafting 
workshops, supporting local artists, varied and flexible use of buildings, community gatherings for socializing and bridging the generation gaps, encouragement of local entrepreneurs, combining anthropic and natural patrimony, involving local community in decision making and volunteering activities, creating a coherent marketing strategy, using new technologies, involving young people in as many local activities as possible, etc.

All in all, Feldioara is the proof that the rural environment is in need of sustainable regeneration and the necessary resources can be found in the high diversity of local cultural and social patrimony, that can create a stronger community, promote environmental protection and generate profits for the local budget, thus reaching all triple bottom line components.

\section{BIBLIOGRAPHY}

Beel D.E., Wallace C.D., Webster G., Nguyen H., Tait E., Macleod M., Mellish C., Cultural resilience: The production of rural community heritage, digital archives and the role of volunteers, Journal of Rural Studies, 54, pp. 589-468.

Borza M, Manolescu I.T. 2015, The implication of international cooperation in the sustainable valorization of rural touristic heritage, Procedia - Social and Behavioural Sciences, 188, pp. 222-229.

Carvalho-Ribeiro S., Correia T. P., Paracchini M. L., Schüpbach B., Sang A. O., Vanderheyden V., Southern A., Jones P., Contreras B. and O'Riordan T. 2016, Assessing the ability of rural agrarian areas to provide cultural ecosystem services (CES): A multi scale social indicator framework (MSCIF), Land Use Policy, 53, pp. 8-19.

Catrina S. 2015, Local heritage interpretation by private cultural agents from Maramures, Procedia - Social and Behavioral Sciences, 188, pp. 174-180.

Cercleux A.L., Bole D. (Eds.) 2019, Strategic guide for developing urban policies in industrial towns, University Press, Bucharest

Cercleux A.L., Merciu F.C., Merciu G.L. 2012, Models of technical and industrial heritage re-use in Romania, Procedia Environmental Sciences, 14, pp. 216-225

Corsale A., Iorio M. 2014 Transylvanian Saxon culture as heritage: Insights from Viscri, Romania, Geoforum, 52, pp. 22-31.

Cucari N., Wankowicz E., De Falco S.E. 2019, Rural tourism and Albergo Diffuso: A case study for sustainable land-use planning, Land Use Policy, 82, pp. 105-119.

Evert K. J. (Ed.) 2010, Encyclopedic Dictionary of Landscape and Urban Planning. Springer Science and Business Media B.V. https://doi.org/10.1007/978-3-540-76435-9 
Gao J., Wu B 2017, Revitalizing traditional villages through rural tourism: A case study of Yuanjia Village, Shaanxi Province, China, Tourism Management, 63, pp. 223-233.

Guzman P., Pereira Roders A., Colenbrander B. 2017, Measuring links between cultural heritage management and sustainable urban development: An overview of global monitoring tools, Cities, 60, pp. 192-201.

Haelg L., Swerin S., Schmidt TS. 2020, The role of actors in the policy design process: introducing design coalitions to explain policy output. Political Science, 54, pp. 309-347, https://doi.org/10.1007/s11077-019-09365-z

Ianoș, I 2004, Dinamica urbană: aplicații la orașul și sistemul urban românesc, Editura Tehnică.

Ianoş I., Cercleux AL., Cocheci RM., Tălângă C., Merciu FC., Manea CA 2021, Smart City Needs a Smart Urban-Rural Interface. An Overview on Romanian Urban Transformations. In: Augusto J.C. (eds) Handbook of Smart Cities. Springer, Cham. https://doi.org/10.1007/978-3-030-15145-4_89-1

Ianoș, I., \& Jones, R 2019, Local aspects of change in the rural-urban fringe of a metropolitan area: A study of Bucharest, Romania, Habitat International, 91(102026), https://doi.org/10.1016/j.habitatint.2019.102026

López-Goyburu, P., \& García-Montero, L. G. 2018, The urban-rural interface as an area with characteristics of its own in urban planning: A review, Sustainable Cities and Society, 43, 157-165, https://doi.org/10.1016/j.scs.2018.07.010

Maloni, M.; Brown, M. 2006, Corporate Social Responsibility in the Supply Chain: An Application in the Food Industry, Journal of Business Ethics, vol. 68, pp. 35-52, Springer.

Nilsson, K., Pauleit, S., Bell, S., Aalbers, C., \& Nielsen, T. S. 2013, Peri-urban futures: Scenarios and models for land use change in Europe. In Peri-Urban Futures: Scenarios and Models for Land use Change in Europe, https://doi.org/10.1007/9783-642-30529-0

Pourzakarya M., Bahramjerdi S.F.N. 2019, Towards developing a cultural and creative quarter: Culture-led regeneration of the historical district of Rasht Great Bazaar, Iran, Land Use Policy, 89.

Rashid M.S.A. 2015, Understanding the past for a sustainable future: Cultural mapping of Malay heritage, Procedia - Social and Behavioural Sciences, 170, pp. 10-17.

Reid K., Beilin R., McLennan J 2020, Communities and responsibility: Narratives of place-identity in Australian bushfire landscapes, Geoforum, 109, pp. 35-43.

Safonte G.F., Trapani F 2017, A theoretical and methodological framework for the analysis and measurement of environmental heritage at local level, Energy Procedia, 115, pp. 487-501

Tweed C., Sutherland M. 2007, Built cultural heritage and sustainable urban development, Landscape and Urban Planning, 83, pp. 62-69.

Yao, Y., Lu, Y., Wang, G., Dong, Y., \& Wang, H. 2018, Relations between global city connectivity of the primary city and the size national economy, Journal of Urban and Regional Analysis, 10(1), 5-23, https://doi.org/10.37043/jura.2018.10.1.1 
***National Institute of Statistics of Romania, available at http://statistici.inssse.ro:80777/ tempo-online, accessed at 10.01.2021.

${ }^{* * *}$ HG Nr. 171/17.12.2015 regarding the approval of Local Development Strategy for Câmpia Turzii Municiaplity for period 2015-2020, available at http://campiaturzii.ro, accessed at 20.12.2020. 